УДК 372.881.1

\title{
ПРЕПОДАВАНИЕ И ИЗУЧЕНИЕ ИНОСТРАННЫХ ЯЗЫКОВ
}

\author{
Степаненко Ирина Семеновна \\ д.м.н., доцент, профессор \\ ФГБОУ ВО «МГУ им. Н.П. Огарева»
}

Аннотация: преподавание и изучение иностранных языков изменились от среды, ориентированной на учителя, к среде, ориентированной на учащихся. Опираясь на языковые теории, результаты исследований и опыт, педагоги разработали стратегии обучения и среды обучения, которые вовлекали учащихся в задачи интерактивного общения. Переход в преподавании иностранного языка от конкретного метода иностранного языка к измерению языковой эффективности/компетенции привел к изменению роли учителя с одного из авторитета/эксперта на роль фасилитатора/гида и агента изменений. Современные разработки указывают на то, что общественная педагогика, социальные сети и практические исследования являются дополнительными способами развития межкультурной компетенции и изучения языка.

Ключевые слова: иностранный язык, языковая педагогика, интерактивное общение, овладение вторым языком.

\section{TEACHING AND STUDYING OF FOREIGN LANGUAGES}

Abstract: teaching and learning foreign languages has changed from a teachercentered environment to a student-centered one. Drawing on language theories, research and experience, educators developed learning strategies and learning environments that engage students in interactive communication tasks. The transition in teaching a foreign language from a specific method of a foreign language to measuring language effectiveness / competence led to a change in the role of the teacher from one of an authority / expert to the role of a facilitator / guide and agent of change. Recent developments indicate that community pedagogy, social media and action research are complementary ways of developing intercultural competence and language learning.

Key words: foreign language, language pedagogy, interactive communication, developing a second language. 
Изучение и преподавание иностранного языка относится к преподаванию или изучению не родного языка вне среды, в которой на нем обычно говорят. Часто проводится различие между «иностранным» и «вторым» изучением языка. Второй язык подразумевает, что учащийся находится в среде, где говорят на приобретенном языке. В области исследований термин «овладение вторым языком» - это общий термин, который охватывает изучение иностранных языков и исследует способность человека изучать языки, отличные от первого, после его приобретения. Научные исследования по приобретению неродного языка включают дисциплины психологии, лингвистики, языковой педагогики, образования, нейробиологии, социологии и антропологии. Запросы инноваций в области обучения и преподавания позволили по-новому взглянуть на успешные стратегии и среды изучения языка, направленные на повышение уровня владения языком и его владения.

Язык считается иностранным, если он в основном изучается в классе и на нем не говорят в обществе, где происходит обучение. Изучение другого языка позволяет человеку эффективно и творчески общаться и участвовать в реальных ситуациях на языке подлинной культуры. Изучение другого языка обеспечивает доступ к точке зрения, отличной от собственной, повышает способность видеть связи между областями контента и способствует междисциплинарной перспективе, в то же время, приобретая межкультурное понимание.

Язык является средством, необходимым для эффективного взаимодействия между людьми, и позволяет лучше понять свой собственный язык и культуру. Изучение языка предоставляет учащемуся возможность получить лингвистические и социальные знания и узнать, когда, как и зачем говорить, кому, каковы национальные стандарты в области образования на иностранных языках $[1$, c. 4]. Языковые ученые различают термины «приобретение» и «изучение»: «приобретение» относится к процессу изучения первого и второго языков естественным образом, без формального обучения, в то время как «изучение» зарезервировано для формального изучения второго или иностранных языков в условиях классной комнаты.

Обычно проводится различие между относительно легким процессом овладение вторым языком у детей и более формальным и сложным овладение вторым языком у взрослых. Обучение иностранному языку относится к преподаванию современного языка, который не является ни официальным языком, ни родным языком значительной части населения. 
Изучение и преподавание иностранного языка претерпели значительные изменения в парадигме в результате исследований и опыта, которые расширили базу научных и теоретических знаний о том, как студенты изучают и приобретают иностранный язык. Традиционно изучение иностранного языка считалось «мимикой», процессом, в котором учащиеся повторяли или подражали новой информации. Основываясь на бихевиористских теориях обучения и структурной лингвистике, качество и количество языка и обратной связи рассматривались в качестве основных факторов, определяющих успех изучения языка. Популярный метод преподавания в 1950-х годах, называемый аудиоязыковым подходом, способствовал имитационному и практическому подходу к развитию языка. Главной фигурой в классе аудиоязыкового подхода был инструктор, который был назначен на роль сержанта, эксперта и авторитетной фигуры. Студенты были вынуждены практиковать и подражать шаблонам до точки автоматического ответа, полагая, что учащийся должен будет просто вставить лексические элементы, соответствующие разговорной ситуации. Считалось, что первый язык мешал приобретению второго языка и, что перевод будет происходить с первого на второй язык, что приведет к ошибкам. В 1959 году рецензия Noam Chomsky's [2, с. 28] на словесное поведение B.F. Skinner's [3, c. 17] резко изменила взгляд на язык, утверждая, что язык - это деятельность, управляемая правилами, а не набор привычек.

N. Chomsky утверждал, что психология стимул-ответ не может адекватно объяснить творческий потенциал, связанный с генерацией новых высказываний с использованием усвоенных правил. Творческий аспект языкового поведения подразумевает, что человеческий разум вовлечен в глубокую обработку значения, а не в заученные реакции на раздражители окружающей среды. Взгляд N. Chomsky на язык и когнитивную психологию, получивший название порождающей трансформационной грамматики, рассматривал овладение языком как внутренний процесс мышления и обучения. N. Chomsky утверждал, что дети биологически запрограммированы на язык и обладают врожденной способностью открывать для себя основные правила языковой системы. Идеи Хомского привели к упадку структурной лингвистики, бихевиористской психологии и аудиоязыкового подхода к изучению языка [2, с. 50].

Возникла альтернативная теоретическая позиция, сосредоточенная на роли языковой среды в сочетании с врожденными способностями ребенка к овладению языком. Эта позиция (интеракционист) рассматривала развитие 
языка как результат сложного взаимодействия между врожденными языковыми способностями учащегося и окружающей средой учащегося. В отличие от позиции иннатиста (например, N. Chomsky), интеракционисты утверждали, что язык должен быть изменен в соответствии со способностями ученика. Согласно Long M.H., языковой ввод стал понятным за счет упрощения ввода, использования лингвистических и внелингвистических сигналов и изменения интерактивной структуры разговора. Long M.H. утверждал, что говорящие корректируют свой язык, когда они взаимодействуют или обсуждают значение с другими. Посредством согласования смысла взаимодействия изменяются и перенаправляются, что приводит к большей понятности. Long M.H. предположил, что учащиеся для того, чтобы овладеть языком, не могут просто прислушиваться к мнению, скорее, они должны быть активными участниками совместной работы, которые взаимодействуют и договариваются о типе ввода, который они получают [4, с. 385].

Каждая из этих теорий овладения языком затрагивает различные аспекты способности ученика овладеть языком. Бихевиористские объяснения объясняют систематические аспекты, тогда как иннатистские объяснения объясняют приобретение сложной грамматики. Интерактивистские объяснения помогают понять, как учащиеся соотносят форму и значение в языке, как они взаимодействуют в разговоре и как они правильно используют язык.

Совсем недавно исследователи определили девять современных теорий изучения языка: универсальная грамматика, автономная индукция, ассоциативно-когнитивное кредо, приобретение навыков, обработка ввода, обрабатываемость, концептуально-ориентированный подход, структура взаимодействия и теория социокультурного развития Выготского Л.С. Некоторые из этих теорий разделяют лингвистический взгляд на языковое познание, другие рассматривают его с психологической точки зрения, а в случае социокультурной теории применяется социальный подход. Универсальная грамматика и теория автономной индукции разделяют лингвистическую точку зрения, согласно которой учащиеся имеют врожденные знания о грамматических структурах, которые не усваиваются путем простого воздействия на входные данные. Они считают, что лингвистическое знание предопределено и не зависит от опыта. Считается, что обучение происходит случайно путем вывода из врожденного абстрактного знания [5].

Психологический взгляд на языковое познание представлен следующими теориями: ассоциативно-когнитивное кредо, теория приобретения навыков, 
теория процессов ввода, теория технологичности, концептуальноориентированный подход и структура взаимодействия. Хотя эти подходы разделяют психологический взгляд на познание, существуют некоторые четкие различия. Теории ассоциативно-когнитивного кредо, обработка ввода, технологичность и концептуально-ориентированные теории рассматривают усвоение языка как неявное, а изучение языка представляется как случайный и подсознательный процесс обучения. Однако в соответствии с теорией приобретения навыков существует осознанная обработка в овладении языком, которая требует явного обучения для того, чтобы произошло преднамеренное обучение.

Самая распространенная и широко распространенная теория, социокультурная теория, предложенная Л. С. Выготским, рассматривает познание как социальную способность. Согласно этой теории, участие в культурно организованных мероприятиях имеет важное значение для обучения. Активное участие в социальном диалоге важно. Обучение рассматривается как преднамеренное, целенаправленное и осмысленное, и оно не является пассивным или случайным процессом, а всегда сознательным и преднамеренным [6]. Согласно Ellis N. C. и Larsen-Freeman D., обучение на опыте происходит «как часть коммуникативно богатой социальной среды человека» [7, с. 577]. Это обсуждается более подробно позже в этой статье.

Исследования показали, что знание языковых структур, продемонстрированных в тестах с дискретными точками, не обеспечивает коммуникативные способности, когда мера языковых знаний является одним из более спонтанных языковых употреблений. Дальнейшие исследования показали, что существует небольшая корреляция между правилами, которым обучаются учащиеся, и их развитием знания второго языка. Ученые-лингвисты продемонстрировали, что некоторые аспекты изучения второго языка не могут быть изменены посредством обучения, и что промежуточные, не родственные языковые навыки, известные как этапы межъязыкового общения, характеризуют развитие овладения вторым языком. Selinker L. pacсматривал межъязыковой язык как промежуточную систему, расположенную на континууме, простирающемся от родного языка до целевого языка [8, с. 36].

Corder S. P. заявил, что в процессе мультиязычности учащийся постоянно и постепенно корректирует систему родного языка для более точного приближения к целевой языковой системе (континуум реструктуризации). 
Corder S. P. отметил, что не все учащиеся продемонстрировали факт перехода от родного языка к целевому языку, и предположил, что в отношении прогресса учащихся, изучающих второй язык, существует единообразие и что они следуют примерно одинаковой последовательности развития независимо от их родного языка (континуума развития) [9, с. 83]. Более поздние исследования в области межъязыкового языка, такие как I. Vidaković изучающий сербов, изучающих английский язык, подтверждают выводы Corder S. P. о том, что язык ученика не только является непрерывным процессом развития, но и является систематическим в своем развитии. Тем не менее, новые результаты содержат доказательства того, что на пути приобретения двух языковых систем учащегося влияет богатое взаимодействие в основном универсальных (в отличие от языковых) факторов, и они демонстрируют сходство, не связанное с первым или вторым языком [10, с. 25].

Согласно этой точке зрения для овладения вторым языком, контролирующим фактором является врожденная способность к изучению языка, которой обладают все люди. Pica $T$. определил, что все изучающие язык проходили через фиксированный ряд этапов, известных как последовательности развития, в изучении определенных языковых подсистем, таких как порядок слов, отрицание или относительные предложения. Отрицание в английском языке, например, при изучении коммуникативных образцов выяснилось, что изучающие иностранный и второй язык проходили одну и ту же четырехэтапную последовательность, определяемую с точки зрения размещения отрицания [11, с. 479]. Ellis N. C. рассмотрел несколько исследований, в которых участвовали японские, испанские, немецкие и норвежские дети, подростки и взрослые учащиеся. Он пришел к выводу, что все изучающие английский как второй язык проходят следующий предписанный набор этапов: (1) фраза «нет», например, «не пить»; (2) отрицатель движется внутри фразы, например, «я не умею плавать»; (3) к модалам прикреплен отрицатель, например, «я не могу сыграть это»; и (4) разработана вспомогательная система, и учащийся получает правильное использование сокращений, например, «Он ничего не знает». Это говорит о том, что учащиеся совершают определенные виды ошибок на определенных этапах приобретения структуры. Каждый этап отмечает некоторую перестройку в сознании учащегося относительно этой конкретной структуры. Структура развивается со временем [12, с. 127]. 
Возможно ли изучение второго языка без правил? В отсутствие правил, возможно, низкоуровневое ассоциативное обучение, основанное на информационных процессах, поддерживаемых памятью, но не приводящее к знанию систематического правила. Будущие исследования должны выяснить, все ли аспекты второго языка одинаково изучаемы неявными средствами или же для более сложных аспектов второго языка может потребоваться более концептуальная обработка для формирования ассоциаций [13, с. 143].

Последние тенденции в изучении иностранных языков все больше фокусируются на многоязычии и взаимодействии нескольких языковых систем в изучении языка. Одной из областей многоязычия, которая много изучалась, является межъязыковое влияние (также известное как языковой перевод, лингвистическое вмешательство, роль родного языка, влияние родного языка и смешение языков) [14, с. 442]. Исследования указывают на сложность и динамичность многоязычной системы и выявили ряд факторов, влияющих на межъязыковое воздействие на приобретение иностранного языка, особенно третьего языка.

Некоторые из этих факторов включают (психо) типологическую дистанцию (например, сходство языков или предполагаемое сходство), эффект иностранного языка (стратегия преодоления трудностей, используемая в качестве типа «когнитивного режима иностранного языка»), уровень владения языком и актуальность использования или контекст взаимодействия [15, с. 143]. Исследования также свидетельствуют о более сильной языковой передаче между вторым и третьим языками, а не третьим и первым языками. Кроме того, в современных исследованиях кросс-лингвистического влияния, как правило, рассматривается каждый аспект овладения языком отдельно (например, фонологический перевод и передача навыков грамотности) и обнаруживается, что не каждый тип перевода работает одинаково или подвержен влиянию одних и тех же факторов [16, с. 81].

Два коммуникативных подхода, модель ввода и модель взаимодействия ввода, представляют две модели теории и преподавания иностранного языка, которые исследуют процесс освоения языка с точки зрения обучающегося. Krashen S. является основным сторонником модели ввода преподавания иностранных языков. Его теория основана на (1) генеративной лингвистике $N$. Chomsky; (2) исследование эффективности различных вторых / иностранных методов обучения; и (3) исследование аффективных факторов (таких как 
мотивация, беспокойство и личность). Krashen S. предположил, что овладение вторым языком происходит, когда учащийся понимает языковой вклад в ситуации с низкой тревожностью и высокой мотивацией, и предположил, что роль учителя заключается в создании такой учебной среды. Krashen S. также утверждал, что сознательное преподавание / изучение грамматики эффективно только в плане контроля за грамматической точностью, а не при овладении самим вторым языком [17, с. 27].

Были проанализированы индивидуальные когнитивные (например, интеллект, способности или способности) и аффективные (например, отношение и личностные переменные) факторы. Skehan P. отметил довольно сильную связь между когнитивными переменными, такими как способности, интеллект и языковые достижения для учащихся в классах иностранных языков. Другие проанализированные факторы включают возраст учащегося [18, с. 171]. Исследователи, как правило, стремились понять, как раннее обучение, а не позднее, влияет на успешное усвоение, и обсуждали эту проблему с точки зрения критического периода освоения, в котором овладение языком, казалось, зависело от соответствующего вклада в течение этого периода времени [19, с. 639].

Хотя эффекты критического периода в обучении второму языку все еще обсуждаются, исследователи в целом соглашаются с тем, что раннее изучение второго языка связано с более высокой конечной способностью, и возраст приобретения надежно является самым сильным предиктором конечных достижений в языке [20, с. 34]. Недавние разработки в области нейролингвистики и нейробиологии подтверждают, что грамматическая обработка второго языка осуществляется с помощью тех же вычислительных устройств мозга, что и в языке первом. Кроме того, было установлено, что умение, возраст приобретения и степень воздействия второго языка сложным образом взаимодействуют с различными типами языковой успеваемости [21, c. 203].

Интересно, что это относится не только к приобретению второго языка, но и к исследованиям визуализации мозга в нейробиологии выявили общую тенденцию, что раннее обучение (любого типа) приводит к выделенной нервной схеме, которая влияет на форму когнитивных и нервных структур на более поздних стадиях развития [19 с. 646]. Более того, исследования показали, что на самом деле возможно достижение широкого сходства с местным 
населением среди поздних учащихся второму языку [19, с. 648] [21, с. 205] [22, с. 41]. Дальнейшие исследования в области приобретения второго языка должны учитывать не только типичное снижение его уровня с возрастом, но также и уровни достижения, подобные нативным, на которые способны некоторые поздние ученики [20, с. 37].

Однако оказалось, что предсказательная сила вышеупомянутых черт снижается по мере того, как критерии владения языком становятся более коммуникативными, а условия обучения - более естественными (по сравнению с формальными и учебными). Наиболее активным занятием в исследованиях были исследования роли мотивации в изучении языка и отношения учащегося к целевому языку и культуре. Используя различие между интегративной и инструментальной мотивацией Gardner $R$. C. and Lambert W. E., исследователи не сообщили о существенном преимуществе интегративного (внутреннего) мотива, а другие сообщили о преимуществе, когда ученик руководствовался инструментальными (внешними) мотивами. Интегративная мотивация была определена как та, в которой целевой язык изучался человеком, чтобы быть принятым сообществом носителей языка. Инструментальная мотивация была той, в которой язык учился на внешние выгоды, такие как обеспечение лучшей работы [23].

Результаты исследований, изучающих факторы окружающей среды, сообщают о влиянии на оценки достижений. Carroll J. В. провел опрос по французскому языку в восьми странах и отметил влияние на успеваемость по полу, типу школы и полу учителя, а также смешанные эффекты в зависимости от интересов родителей. Было установлено, что социальные факторы за пределами школы оказывают существенное влияние на развитие языковых навыков. Как когнитивные, так и аффективные факторы были исследованы, чтобы объяснить разницу в достижении иностранных языков [24, с. 67]. Мотивация, отношение, беспокойство, самооценка, терпимость к двусмысленности, риск, сотрудничество и конкуренция оказались ключевыми переменными, объясняющими индивидуальные различия в изучении иностранных языков. Было установлено, что успешное изучение языка во многом зависит от того, кто изучает язык, при каких обстоятельствах и для каких целей. Было установлено, что овладение иностранным языком является сложным, многомерным процессом, на который влияют как переменные ученика, так и переменные среды. Вопросы, порожденные этими теориями и 


\section{АНАЛИЗ СОСТОЯНИЯ, ПРОБЛЕМ И ПЕРСПЕКТИВ РАЗВИТИЯ

научными исследованиями, стали фокусироваться на новых важных обязанностях учителя в разработке и поддержке индивидуальных и персонализированных учебных задач [25, с. 231].

В преподавании языка произошли многочисленные нововведения в учебных планах в связи с важностью предоставления студентам возможности овладеть и практиковать иностранный язык в контекстуализированных и содержательных языковых коммуникативных задачах на всех этапах процесса освоения второго или иностранного языка. Коммуникативное преподавание языка, термин, наиболее ассоциируемый с текущим обсуждением метода, возник как значительный подход, который нашел универсальный резонанс и поддержку в теории и применении во многих контекстах и в разных дисциплинах (лингвисты, методологи и разработчики учебных программ). Центральным моментом в развитии коммуникативного преподавания языка было осознание того, что лингвистическая компетентность сама по себе не достигает коммуникативной компетенции и что язык, используемый в значимых, аутентичных контекстах, легче усваивается [16, с. 5].

Парная работа, групповая работа, условия для совместного обучения, аутентичные материалы, культурно интегрированный контент урока и интерактивные задания, ориентированные на когнитивную и аффективную сферы, были интегрированы в классы иностранных языков. Кроме того, был призыв к переосмыслению теоретических основ, связанных с использованием целевого языка для языкового обучения.

В прошлой учебной политике доминировали одноязычные принципы обучения, в значительной степени не подкрепленные эмпирическими данными. В современных многоязычных классных комнатах необходимо пересмотреть общие предположения о том, что перевод со второго на первый язык (или третьего на второй язык в этом отношении) не имеет места в преподавании языка или грамотности, что обучение должно осуществляться исключительно на целевом языке без обращения к первому языку студентов, и что первый и второй языки должны быть жестко разделены. В отличие от этих предположений, недавние исследования пролили свет на тот факт, что первый язык следует рассматривать как когнитивный и лингвистический ресурс, который может выступать в качестве трамплина для поддержки более эффективной работы в языке втором [27, с. 238].

Кроме того, конструктивистские методы обучения, на которые оказал влияние К.С. Выготский, уделяющий особое внимание социальному 
взаимодействию в процессе обучения и развития, помогли учащимся усвоить и изменить новую информацию. Теоретические основы взглядов К.С. Выготского на изучение языка, которые поддерживали контекстуальный вклад в кооперативные, содержательные взаимодействия с другими, легли в основу социокультурной теории, которая расширила владение языком и получила распространение в классных комнатах по всему миру [6]. Согласно Lantolf J. и Pavlenko A., цель социокультурной теории - понять, как люди организуют свой разум и используют его в повседневной жизни. С социокультурной позиции овладение языком представляет собой нечто большее, чем просто овладение лингвистическими свойствами второго языка. Он включает в себя «диалектическое взаимодействие двух способов создания смысла в мире» [28, c. 110].

Взаимодействие между экспертом (учителем) и новичком (учеником) в решении задачи (строительные леса), в которой роль эксперта состояла в том, чтобы обеспечить новичка учебной поддержкой, стало моделью для коммуникативных задач в классах иностранных языков. Исходя из концепции Выготского о зоне ближайшего развития (расстояние между фактическим уровнем развития и уровнем потенциального развития), роль эксперта и учителя заключалась в том, чтобы заинтересовать ученика в задаче, упростить задачу, сохранить мотивацию ученика, укажите важные особенности, уменьшите беспокойство и разочарование при решении проблем и смоделируйте соответствующую форму. В соответствии с новыми обязанностями роль учителя в классе сместилась на роль архитектора, создавая осмысленные, интерактивные и совместные учебные задачи, предназначенные для активного вовлечения учащегося в согласование языкового значения в аутентичных контекстах, которые создаются совместно.

Сосредоточение внимания на владении языком учащихся, измеряемое с помощью задач, основанных на успеваемости, проявилось как в исследованиях по изучению языка, так и в преподавании. Возникли вопросы о том, как повысить уровень владения языком и как наилучшим образом измерить уровень владения языком.

Поскольку движение профессионалов набирает обороты в США и совсем недавно в Европе, был достигнут консенсус относительно описания и измерения языковых способностей. Разработка Руководства по повышению квалификации American Council on the Teaching of Foreign Languages (ACTFL) 
[29] определила, какие языковые пользователи могут делать с языком при разговоре, аудировании, чтении и письме на разных уровнях производительности. В этих руководящих принципах отмечен значительный сдвиг в языковой педагогике от методологии к измерению и акцент на результатах учащихся. В 1996 году были опубликованы стандарты контента, которые впоследствии были пересмотрены («National Standards in Foreign Language Education Project», 1996, 2006 и 2014 годы), в которых указано, что учащиеся должны знать и уметь делать с языком. В Руководстве по успеваемости ACTFL для учащихся K-12 [29 ] описана языковая эффективность в трех режимах общения (межличностном, интерпретативном и презентационном), чтобы помочь учителям понять, насколько хорошо учащиеся демонстрируют языковые способности в различных точках языкового континуума. Аналогичные усилия International Association for the Evaluation of Educational Achievement's Language Education Study направлены на сравнение и оценку результатов различных систем образования в Европе. Движение за стандарты, стремясь содействовать разработке руководящих принципов преподавания иностранных языков для всех учащихся, свидетельствует о растущем интересе к результатам и подотчетности учащихся. В среде, основанной на стандартах, переход к успеваемости учащихся требует, чтобы учителя обладали набором подходов, ориентированных на конкретные цели или стандарты.

Все чаще преподаватели языка утверждают, что изучение иностранного языка должно повысить межкультурную компетенцию учащихся, которая позволит им видеть отношения между различными культурами, осуществлять посредничество между этими культурами и критически анализировать культуры, в том числе и свои [30, с. 28]. Преподаватели языка уже осознали свою роль в выявлении культурных знаний в своих классных комнатах и способах доступа к ним [31, с. 297]. Одним из таких способов, предложенных Schulz R. A., является использование портфелей для обучения культуре. По словам Schulz R. A., обучение межкультурной компетенции должно включать развитие понимания переменных, которые влияют на коммуникативные взаимодействия, распознавание стереотипов и их оценку, а также развитие понимания типов причин культурных недоразумений между представителями разных культур. Использование портфеля культурного обучения позволяет учителям оценивать успеваемость учащихся с течением времени на основе 
конкретных целей, которые могут быть связаны с индивидуальными интересами учащихся. Эти портфели способствуют критическому размышлению и самооценке и, что особенно важно в области культурного обучения, использованию множества источников данных [32, с. 18]. Несмотря на многочисленные исследования эффективных стратегий и подходов к обучению и оценке межкультурной компетенции в классах иностранных языков (особенно в Соединенных Штатах), было выдвинуто несколько проблем. Одной из таких задач является повышение осведомленности студентов о ценности взгляда на мир через язык / культуру другого человека и создание более эффективного климата для развития межкультурной компетенции в среде, где моноязычная монокультурная национальная языковая идентичность правит дома, а глобальный английский - за рубежом [33, с. 117].

Одной из областей, которая остается противоречивой в мире обучения иностранному языку и второму языку сегодня, является вопрос: является ли достижение, подобное родному, необходимой или желательной целью в глобальном мире, в котором мы живем сегодня? В области английского языка как иностранного в последние годы широко обсуждается вопрос о том, должны ли носители соответствовать нормам английского языка в свете его все более широкого использования в международном контексте [34, с. 241]. В свете этой проблемы многие ученые в этой области подняли вопрос о том, почему сообщества носителей языка чаще всего являются моделью для изучающих английский язык как международный язык. В ответ на это был разработан поток терминов (например, Global English, International English, International Standard English, World English, World English), некоторые из которых ставят под сомнение идею о том, что оцениваются только разновидности сообщества носителей языка. Сторонники термина «Global English», например, продвигают идею о том, что английский язык принадлежит всем, кто его использует, однако они его используют [35, с. 4].

Другим важным направлением в исследованиях, которое требует большего внимания, является использование и влияние компьютерных технологий на изучение иностранных языков. Поскольку задачи в классе становятся более сфокусированными на реальных проблемах, текстах или событиях и задачах, основанных на решении проблем, технология вводит новое измерение в процесс преподавания и обучения, которое включает использование социальных сетей, таких как Facebook, Twitter, Skype, Voice 
Thread и другие. Цифровые медиа позволяют студентам манипулировать учебными материалами и языком в своем собственном темпе и в соответствии с индивидуальными потребностями. Студенты изучают отчеты, аутентичные документы и веб-страницы, чтобы найти информацию, которая может быть обобщена и обсуждена позже и может в электронном виде сотрудничать с молодежью со всего мира. В такой учебной среде роль учителя меняется с роли авторитетного деятеля или эксперта, который передает знания тому, кто облегчает, направляет и поддерживает обучение студентов. Учитель принимает на себя большую ответственность за разработку и поддержку индивидуальных и персонализированных учебных задач. Это имеет огромное значение для педагогов и инструкторов преподавателей, чтобы они выступали в качестве агентов изменений, поскольку они способствуют изучению языка посредством использования общественной педагогики и критической медиаграмотности. Одной из наиболее эффективных исследовательских методологий, появившихся в последние несколько лет, было исследование действий. Изучая собственную методику преподавания с помощью исследований в классе, учителя активно участвуют в исследовательской деятельности и изменяют практики на основе полученных результатов. Такие исследования обещают улучшить методы преподавания, которые представляют интерес как для исследователей, так и для преподавателей.

Методологически ориентированные на аудиторию исследования проводились в основном в рамках корреляционных подходов, тематических исследований, опросов, этнографических исследований, экспериментов и дискурс-анализа [36]. Хотя выбор метода исследования в значительной степени определяется характером исследуемого вопроса или гипотезой, подлежащей проверке, продуманные комбинации качественного и количественного исследования условий изучения иностранного / второго языка обеспечат ценную информацию о процессах изучения языка. Необходимо и рекомендуется шире использовать качественные и смешанные методы исследования учащихся в их классах с особым вниманием к культурным, ситуационным и продольным контекстам. Поскольку исследования иностранных языков основаны на смежных дисциплинах (психологии, психолингвистике, нейробиологии, нейролингвистике, социологии и лингвистике), чтобы лучше объяснить условия, которые приводят к повышению уровня владения языком и различному успеху среди изучающих 
иностранный язык, более глубокое понимание того, как языки приобретаются и, следовательно, как их следует учить, многие осознали. Кроме того, по мере того, как инновации в обучении и преподавании продолжают испытываться и исследоваться, будут получены новые идеи, которые повлияют на практику преподавания во всем мире.

\section{Список литературы}

1. National Standards in Foreign Language Education Project (NSFLEP), 2014. World Readiness Standards for Learning Languages (WRSLL). Alexandria. 46 pp.

2. Chomsky, N., 1959. Review of verbal behavior by B.F. Skinner. Language 35, pp. 26-58.

3. Skinner, B. F., 1957. Verbal Behavior. Methuen, London. 708 pp.

4. Long, M. H., 1985. Input and second language acquisition theory. In: Gass, S., Madden, C. (Eds.), Input in Second Language Acquisition. Newbury House, Rowley, MA, pp. 377-393.

5. VanPatten, B., Williams, J. (Eds.), 2008. Theories in Second Language Acquisition: An Introduction. Routledge Taylor \& Francis Group, New York. 261 p.

6. Vygotsky, L.S., 1978. Mind in Society: The Development of Higher Psychological Processes. Harvard University Press, Cambridge, MA. 133 pp.

7. Ellis, N. C., Larsen-Freeman, D., 2006. Language emergence; implications of applied linguistics-introduction to the special issue. Applied Linguistics 27, pp. 558-589.

8. Selinker, L., 1974. Interlanguage. In: Schumann, J. H., Stenson, N. (Eds.), New Frontiers in Second Language Learning. Newbury House, Rowley, MA. 209 pp.

9. Corder, S. P., 1978. Language-learning language. In: Richards, J. C. (Ed.), Understanding Second and Foreign Language Learning: Issues and Approaches. Newbury House, Rowley, MA, pp. 71-93.

10. Vidaković, I., 2010. Second language acquisition of dynamic spatial relations. Research and Validity Group, Cambridge ESOL 42, pp. 23-33.

11. Pica, T., 1983. Adult acquisition of English as a second language under different conditions of exposure. Language Learning 33, pp. 465-497.

12. Ellis, R., 1986. Understanding Second Language Acquisition. Oxford University Press, Oxford, UK. 327 pp.

13. Ellis, N.C., 2002. Frequency effects in language processing. Studies in Second Language Acquisition 24, pp. 143-188. 
14. Odlin, T., 2003. Cross-linguistic influence. In: Doughty, C., Long, M. (Eds.), The Handbook of Second Language Acquisition. Blackwell, Malden, MA, pp. 436-486.

15. De Angelis, G., 2007. Third or Additional Language Acquisition. Clevedon: Multilingual Matters. 168 pp.

16. Wrembel, M., 2010. L2 accented speech in L3 production. International Journal of Multilingualism 7 (1), pp. 75-90.

17. Krashen, S., 1982. Principles and Practice in Second Language Acquisition. Pergamon, Oxford, UK. 202 pp.

18. Skehan, P., 1986. The role of foreign language aptitude in a model of school learning. Language Testing 3, pp. 188-221.

19. Hernandez, A.E., Ping, L., 2007. Age of acquisition: its neural and computational mechanisms. Psychological Bulletin 133 (4), pp. 638-650.

20. Birdsong, D., 2006. Age and second language acquisition and processing: a selective overview. Language Learning 56, pp. 9-49.

21. Perani, D., Abutalebi, J., 2005. The neural basis of first and second language processing. Current Opinion in Neurobiology 15 (2), pp. 202-206.

22. Marinova-Todd, S., 2003. Comprehensive Analysis of Ultimate Attainment in Adult Second Language Acquisition (Unpublished doctoral dissertation). Harvard University. $156 \mathrm{pp}$.

23. Gardner, R. C., Lambert, W. E., 1972. Attitude and Motivation in Second Language Learning. Newbury House, Rowley, MA. 313 pp.

24. Carroll, J. B., 1975. The Teaching of French as a Foreign Language in Eight Countries. Wiley, New York. 281 pp.

25. Ellis, R., 1994. The Study of Second Language Acquisition. Oxford University Press, Oxford, UK. 824 pp.

26. Canale, M., Swain, M., 1980. Theoretical bases of communicative approaches to second language teaching and testing. Applied Linguistics 1, pp. 1-47.

27. Cummins, J., 2010. Rethinking monolingual instructional strategies in multilingual classrooms. Canadian Journal of Applied Linguistics (CJAL) 10, pp. 221-241.

28. Lantolf, J., Pavlenko, A., 1995. Sociocultural theory and second language acquisition. Annual Review of Applied Linguistics 15, pp. 108-124.

29. ACTFL, 2006. ACTFL Performance Guidelines for K-12 Learners. American Council on the Teaching of Foreign Languages, Yonkers, NY. 22 pp. 
30. Chapelle, C., 2010. If intercultural competence is the goal, what are the materials?. In: Proceedings of CERCLL Intercultural Competence Conference. CERCLL, Tucson, Arizona, pp. 27-50.

31. Moloney, R., Harbon, L., 2010. Making intercultural language learning visible and assessable. In: Proceedings of CERCLL Intercultural Competence Conference. CERCLL, Tucson, Arizona, pp. 281-303.

32. Schulz, R.A., 2007. The challenge of assessing cultural understanding in the context of foreign language instruction. Foreign Language Annals 40 (1), pp. 9-26.

33. Fonseca-Greber, B., 2010. Social obstacles to intercultural competence in American language classrooms. In: Proceedings of CERCLL Intercultural Competence Conference. CERCLL, Tucson, Arizona, pp. 102-123.

34. Timmis, I., 2002. Native speaker norms and international English: a classroom view. ELT Journal 56 (3), pp. 240-249.

35. McArthur, T., 2001. World English and world Englishes: trends, tensions, varieties and standards. Language Teaching 34, pp. 1-20.

36. Johnson, D.M., 1992. Approaches to Research in Second Language Learning. Longman, White Plains, NY. 288 pp. 